\title{
Can people-centered community-oriented interventions improve skilled birth attendance? Evidence from a quasi- experimental study in rural communities of Cambodia, Kenya, and Zambia
}

\author{
Anbrasi Edward ${ }^{1 *}$ (D), Aparna Krishnan², Grace Ettyang ${ }^{3}$, Younghee Jung ${ }^{4}$, Henry B. Perry ${ }^{1}$, Annette E. Ghee ${ }^{5}$ and
} Jane Chege ${ }^{6}$

\begin{abstract}
Background: Skilled attendance at delivery is a key marker for reducing maternal mortality. Effective community engagement strategies complemented by community health worker (CHW) services can improve access to maternal health services in areas with limited health infrastructure or workforce.

Methods: A quasi-experimental study with matched comparison groups was conducted in Cambodia, Kenya and Zambia to determine the effect of integrated community investments on skilled birth attendance (SBA). In each country, communities in two districts/sub-districts received a package of community-oriented interventions comprised of timed CHW household health promotion for maternal, newborn and child health complemented by social accountability mechanisms using community scorecards. Two matched comparison districts/sub-districts received ongoing routine interventions. Data from the final evaluation were examined to determine the effect of timed CHW services and community-oriented interventions on SBA.
\end{abstract}

Results: Over 80\% of the 3037 women in Cambodia, 2805 women in Kenya and 1171 women in Zambia reported SBA. Women in intervention sites who received timely CHW health promotion and social accountability mechanisms in Cambodia showed significantly higher odds of SBA (aOR $=7.48 ; 95 \% \mathrm{Cl}: 3.87,14.5)$. The findings also indicated that women over the age of 24 in Cambodia, women with primary or secondary education in Cambodia and secondary education in Kenya, women from higher wealth quintiles in Cambodia, and women with four or more antenatal care (ANC) visits in all countries reported significantly higher odds of SBA. Inclusion of family members in pregnancy-related discussions in Kenya $(\mathrm{aOR}=2.12 ; 95 \% \mathrm{Cl}: 1.06,4.26)$ and Zambia $(\mathrm{aOR}=6.78 ; 95 \% \mathrm{Cl}$ : $1.15,13.9)$ and follow up CHW visits after a referral or health facility visit ( $\mathrm{aOR}=2.44 ; 95 \% \mathrm{Cl}$ : 1.30, 4.60 in Cambodia; $\mathrm{aOR}=2.17 ; 95 \% \mathrm{Cl} 1.25,3.75$ in Kenya; $\mathrm{aOR}=1.89 ; 95 \% \mathrm{Cl}: 1.05,2.02$ in Zambia) also showed significantly greater odds of SBA.

(Continued on next page)

\footnotetext{
* Correspondence: aedward1@jhu.edu

'Department of International Health, Johns Hopkins Bloomberg School of

Public Health, 615 N Wolfe St, Baltimore, MD 21205, USA

Full list of author information is available at the end of the article
}

C C The Author(s). 2020 Open Access This article is licensed under a Creative Commons Attribution 4.0 International License, which permits use, sharing, adaptation, distribution and reproduction in any medium or format, as long as you give appropriate credit to the original author(s) and the source, provide a link to the Creative Commons licence, and indicate if changes were made. The images or other third party material in this article are included in the article's Creative Commons licence, unless indicated otherwise in a credit line to the material. If material is not included in the article's Creative Commons licence and your intended use is not permitted by statutory regulation or exceeds the permitted use, you will need to obtain permission directly from the copyright holder. To view a copy of this licence, visit http://creativecommons.org/licenses/by/4.0/. The Creative Commons Public Domain Dedication waiver (http://creativecommons.org/publicdomain/zero/1.0/) applies to the data made available in this article, unless otherwise stated in a credit line to the data. 
(Continued from previous page)

Conclusions: Enhancing people-centered care through culturally appropriate community-oriented strategies integrating timely CHW health promotion and social accountability mechanisms shows some evidence for improving SBA during delivery. These strategies can accelerate the achievement of the sustainable development goals for maternal child and newborn health.

Keywords: Skilled birth attendance, Community health workers, Social accountability mechanisms, Community scorecards

\section{Background}

Recent evidence from the World Health Organization indicates that globally almost $80 \%$ of births are now assisted by skilled personnel during delivery [1]. However, inequities still exist as low- and middle-income countries (LMIC) account for approximately 99\% (302, 000) of the global maternal deaths, with sub-Saharan Africa accounting for approximately $66 \%(201,000)$ of these deaths [2]. Economic and ethnic disparities are also evident in poorer countries based on the progress reports for the Millennium Development Goals [3]. Maternal mortality reduction remains a priority under the Sustainable Development Goal 3.1 with a target of less than 70 deaths per 100,000 live births by 2030 [2].

The majority of maternal deaths are preventable in LMICs, as $75 \%$ of all maternal deaths are caused by postpartum hemorrhage, hypertensive disorders of pregnancy (pre-eclampsia/eclampsia), infections, unsafe abortions and other delivery-related complications $[4,5]$. High maternal mortality rates in LMIC have been associated with poor access to quality healthcare services during the antenatal, delivery and postnatal periods [6]. Accessible and quality antenatal care (ANC) and skilled birth attendance (SBA) during delivery have been shown to improve the survival and health outcomes of women in sub-Saharan Africa and Southeast Asia [7]. Evidence from studies has shown than $16-33 \%$ of maternal deaths can be averted with SBA at the time of delivery $[4,8-10]$.

In a recent systematic review of studies in LMICs, deliveries conducted within health facilities resulted in a $29 \%$ reduction in neonatal mortality; however, these results were found only within a conducive environment with skilled staff and emergency obstetrical facilities [11]. Several studies have shown that health facilitybased deliveries may not be realistic for women living in rural and remote areas of LMIC due to poor physical access, long distances to facilities, and poor quality of services [11]. Furthermore, large proportions of unskilled deliveries still occur within health facilities [12]. Therefore, ensuring SBA at delivery, as opposed to facilitybased deliveries, may be more appropriate to achieve when designing interventions to improve maternal outcomes for rural communities.
Several individual and contextual factors influence SBA during delivery. These include maternal age, parity, socio-economic status, education, cultural beliefs, access to quality and affordable care, and overall trust in the local healthcare system [13-16]. There is strong evidence that health promotion provided by community health workers $(\mathrm{CHW})$ within the household, behavior change communication campaigns, early recognition of obstetrical complications, and prompt referral to higher levels of care can reduce delays in care-seeking and promote SBA during delivery [17]. CHWs perform a wide range of health promotion activities during home visits. These include treatment support, home-based care, promotion and facilitation of ANC attendance, use of culturally-acceptable educational strategies, engagement of family members in pregnancy-related care, and planning for a facility delivery [18]. However, few studies have explored the effect of various components of $\mathrm{CHW}$ service delivery on maternal care-seeking practices.

As a supportive mechanism for CHW systems, social accountability mechanisms using community scorecards have been integrated to improve health service utilization, including maternal and child health services in LMIC contexts [19-22]. The activities are focused to strengthen community engagement and people centered care by mobilizing communities and facility-oriented accountability mechanisms with health providers to improve service utilization and quality of care.

World Vision, a Christian relief and development organization, has made substantial investments in community-based health globally for maternal and child health in LMIC. These projects are implemented through comprehensive Area Development Programs and cover a wide range of services, including safe water and sanitation, health and nutrition education, child protection, food security and livelihood improvements. A multi-country mixed methods research study was conducted to determine the combined interventions of targeted $\mathrm{CHW}$ services and community oriented social accountability mechanisms using community scorecards on maternal, newborn and child health and nutrition. This study examines the associations between the timed and targeted CHW services and SBA at delivery. 


\section{Methods}

The 5-year multi-country research study was conducted between 2012 and 2017 in Cambodia, Kenya, Guatemala and Zambia by the Johns Hopkins University, the National Institute of Public Health in Cambodia, the Institute of Nutrition of Central America and Panama in Guatemala, Moi University School of Public Health in Kenya, and the Institute of Economic and Social Research at the University of Zambia. This analysis does not include results from the Guatemala study sites.

\section{Study design}

The research was designed as a two-arm quasi experimental study in between September 2013 and September 2017. In each country, four districts or sub-districts with a population ranging from 19,000 to 25,000 were selected. Two districts/sub districts in each country were assigned to the intervention arm and two matched to the comparison arm based on several population, demographic, and access factors (population size, migratory patterns, accessibility to health facilities, disease burden, the presence of other health and non-health developmental programs, maturity and capacity of the World Vision Area Development programs) (Table 1).

All selected study sites received regular programming from World Vision in the areas of water and sanitation, child protection, livelihood and economic development, and education. The study intervention was designed for a period of 24-36 months to enhance maternal, newborn, and child health. In the intervention sites, two combined interventions were launched; 1. Existing CHWs (and those newly recruited under the Ministry of Health in Cambodia) received a multi-phased training with three modules to provide targeted household health promotion and behavior change counseling and services at strategic stages during pregnancy, delivery, postpartum, and the early childhood period. 2. Social accountability mechanisms using Community Voice and Action and Community Scorecards were established to foster community governance and accountability and support health facility operations. Additional details on the mechanisms for social accountability for World Vision's Community Voice and Action and Community Scorecards can be found elsewhere [23]. In both the intervention and comparison sites, World Vision facilitated the formation of facility management committees and community councils or strengthened existing

Table 1 Selected Study Sites in Each Country

\begin{tabular}{|c|c|c|c|c|}
\hline Study Sites & Interven & tion & Comparison & \\
\hline Cambodia & Chulkiri & Comapa & Prasath Balang & Tbeng Meanchey \\
\hline Kenya & Karemo & Katito & Kegonga-Ntimaru & Magunga \\
\hline Zambia & Luampa & Magoye & Choongo & Nyimba \\
\hline
\end{tabular}

councils to support CHWs and their services, using the Global Fund's Community Systems Strengthening Framework [24]. The comparison sites continued to receive health services from the local district, and other development organizations including routine government supported CHW services.

In Cambodia, CHWs comprised of government-recruited Village Health Support Groups. Those in the intervention sites were trained in the timed and targeted counseling interventions. To augment the CHW workforce, additional CHWs were recruited and trained under the government program. Another cadre of Mother Groups were also trained in Cambodia as a supportive system for the CHWs. In Kenya the community health volunteers recruited by the government were trained using a cascade training strategy. World Vision teams trained the government staff, who trained the volunteers in timed and targeted counseling in the intervention sites. It is important to mention that in Kenya, the government had a very structured CHW system, with recruiting guidelines, tasks, reporting and supervision support with community health supervisors in all study sites. In Zambia, a cadre of community-based volunteer groups, termed Safe Motherhood Action Groups, established by the government's safe motherhood program, were trained in timed and targeted counseling. Hence CHW recruitment, initial training, hours of work, task expectations, households covered (50-150), incentive systems, supervision, etc. varied in different countries.

We performed a multi-stage sampling strategy to select communities as sampling units in proportion to their population size. Households meeting the eligibility criteria were randomly selected for the interviews from each sampling unit. One eligible woman aged 15-49 years who was pregnant or had delivered in the previous 2 years and one child younger than 5 years of age were selected randomly from each eligible household. Sample size estimates were based on expected increase in skilled birth attendance. A two-sided alpha of 0.05 and power of 0.80 was used to determine the required sample size, with adjustments for non-response rate (5\%) and a design effect of 1.2.

Interviewers with household survey experience received training on survey field procedures, ethics and informed consent. Appropriate quality control measures were employed for translation and field testing of instruments, data collection, and participant confidentiality. Structured household surveys, modified from the Demographic Health Surveys, were administered to all heads of households to obtain socio-demographic, food security, water and sanitation, and wealth asset information. Eligible women, 15-49 years, who were pregnant or delivered in the 2 years preceding the survey were interviewed using the Women's survey, modified from the Demographic Health Surveys to obtain information on 
reproductive history, care-seeking behaviors, and utilization of health services for maternal, child and newborn health. The English language version of the women's survey is included as a supplementary file. The Johns Hopkins University and local country Institutional Review Board approved informed written consent was obtained from all study participants in Kenya and Zambia, and verbal consent in Cambodia.

Facility-based ANC was defined as pregnancy-related care at a government or private hospital or clinic. A composite ANC Services Index (based on the WHO recommendations) was computed with a score of $0-12$, with equal weight for the individual ANC services the woman received [25]. The ANC Services Index included: two doses of tetanus toxoid vaccine, iron or folate pills, antimalarial medications (in accordance with country policies), pregnancy-related nutrition counseling, counseling about the importance of danger signs in pregnancy, information on where to access care for antenatal or obstetrical complications, HIV testing, counseling on prevention of mother-to-child transmission of HIV, weight and blood pressure measurements, and testing of urine and blood.

To assess the degree and quality of pregnancy-related care provided by CHWs, we determined the number of $\mathrm{CHW}$ visits a woman received from the time of conception to delivery for her most recent pregnancy and other CHW service delivery quality indicators (CHW being courteous and respectful, woman's satisfaction with CHW care, use of counseling aids or illustrated storybooks, pregnancy-related $\mathrm{CHW}$ counseling at home, inclusion of influential family members in pregnancyrelated discussions, provision of information on pregnancy complications, discussion of solutions for any pregnancy-related problems, assistance with access to ANC, and follow up visits if the woman was referred to or visited a health center during her pregnancy). SBA was defined as deliveries that occurred in the presence of a doctor, clinical officer, nurse or midwife.

Standard quality control procedures were employed to clean, verify and analyze data using STATA 14 [26]. A principle components analysis using 12 household assets (television, radio, bicycle, etc.) and household type (type of roof, drinking water source, type of sanitation, etc.) were used to construct wealth quintiles. A descriptive analysis was performed by computing frequencies across the Intervention and Comparison sites, and $t$ tests and chi-squared tests were performed to determine differences between intervention and comparison sites. Univariate logistic regressions were constructed to determine factors associated with SBA for maternal deliveries. The presence of collinearity among the independent variables used in the regression models was tested. Analyses were conducted separately for each country as contextual factors would inherently vary among the countries. Final models providing estimates of odds ratios for SBA were adjusted for: mother's age, education, parity, wealth quintile, treatment arm, receiving 4 or more facility-based ANC visits, and ANC index score. The analysis includes results from the final evaluation, as there were minor variations in the baseline instruments. In Cambodia, a total of 3037 women were enrolled in the final evaluation, and 3037 were included in the analysis on SBA delivery care. In Zambia, 1194 women were enrolled, and 1171 included in the analysis, with a $1.9 \%$ missingness. Kenya had the highest missingness, $10.3 \%$, as 3128 women were enrolled and only 2805 were included in the analysis. Missing records were eliminated from the analysis.

\section{Results}

\section{Sociodemographic characteristics}

Table 2 provides selected sociodemographic characteristics of women 15-40 years who reported a delivery in the past 2 years; 3037 in Cambodia, 2805 in Kenya and 1171 women in Zambia. More than $85 \%$ of households were headed by a male across all sites in both Cambodia and Kenya. In Zambia, less than 50\% of households were headed by males in the intervention sites, compared to $70 \%$ in the comparison sites. In all three countries, most of the women were 20-36 years of age. More than $80 \%$ of the women were married in Cambodia and Kenya, while 70 to $75 \%$ of the women were married in Zambia.

In all three countries, more than $70 \%$ of the women had completed at least primary education, although this proportion was higher in Kenya compared to the other two countries. Approximately one-fourth of the women had access to health insurance in Cambodia, but this was not reported for Kenya or Zambia. Significant differences were evident between comparison and intervention sites for the following variables; male headed households (Kenya and Zambia), mean family size (Cambodia and Kenya), marital status (Kenya), education (Cambodia, Kenya and Zambia), health insurance (Cambodia) and wealth quintile (Cambodia, Kenya and Zambia).

\section{Antenatal and delivery care}

Characteristics of ANC and delivery care are shown in Table 3. The WHO standard of receiving at least 4 or more facility-based ANC visits was significantly higher in the intervention sites for Cambodia $(81.2 \%$ vs $58 \%$, $p<0.001)$ and Kenya $(70.5 \%$ vs $62.7 \%, \mathrm{p}<0.001)$ but was significantly higher in the comparison sites in Zambia $(59.6 \%$ vs $73.2 \%, \mathrm{p}<0.001)$. In Cambodia, the mean month of women's first ANC visit was the first trimester, whereas women in Kenya and Zambia tended to access ANC during the second trimester. 
Table 2 Sociodemographic characteristics of study population by country

\begin{tabular}{|c|c|c|c|c|c|c|c|c|c|}
\hline \multirow[t]{2}{*}{ Characteristics } & \multicolumn{3}{|l|}{$\begin{array}{l}\text { Cambodia } \\
N=3037\end{array}$} & \multicolumn{3}{|l|}{$\begin{array}{l}\text { Kenya } \\
N=2805\end{array}$} & \multicolumn{3}{|l|}{$\begin{array}{l}\text { Zambia } \\
N=1171\end{array}$} \\
\hline & $\begin{array}{l}\mathrm{I}=1261 \\
\mathrm{n}(\%)\end{array}$ & $\begin{array}{l}\mathrm{C} \\
N=1776 \\
\mathrm{n}(\%)\end{array}$ & $\begin{array}{l}p \\
\text { value }\end{array}$ & $\begin{array}{l}\mathrm{N}=1590 \\
\mathrm{n}(\%)\end{array}$ & $\begin{array}{l}\mathrm{C} \\
N=1215 \\
\mathrm{n}(\%)\end{array}$ & $\begin{array}{l}p \\
\text { value }\end{array}$ & $\begin{array}{l}\mathrm{I}=634 \\
\mathrm{n}(\%)\end{array}$ & $\begin{array}{l}\mathrm{C} \\
N=537 \\
\mathrm{n}(\%)\end{array}$ & $\begin{array}{l}p \\
\text { value }\end{array}$ \\
\hline Male-headed household & $1130(89.8)$ & $1584(89.5)$ & 0.815 & $1360(86.4)$ & $1076(89.3)$ & 0.022 & $288(46.3)$ & $368(69.7)$ & $<0.001$ \\
\hline Mean family size & 5.1 & 4.8 & $<0.001$ & 4.9 & 4.8 & 0.021 & 5.3 & 5.2 & 0.173 \\
\hline \multicolumn{10}{|l|}{ Mother's age (in years) } \\
\hline $15-19$ & $49(3.9)$ & $81(4.6)$ & 0.359 & $140(8.8)$ & $100(8.2)$ & 0.588 & $97(15.3)$ & $86(16)$ & 0.738 \\
\hline $20-36$ & $1113(88.3)$ & $1536(86.5)$ & 0.144 & $1334(83.9)$ & $1040(85.6)$ & 0.214 & $455(71.8)$ & $394(73.4)$ & 0.540 \\
\hline $37-49$ & $99(7.8)$ & 159 (8.9) & 0.279 & $116(7.3)$ & $75(6.2)$ & 0.237 & $82(12.9)$ & 57 (10.6) & 0.219 \\
\hline \multicolumn{10}{|l|}{ Marital status } \\
\hline Married & $1239(98.3)$ & $1744(98.2)$ & 0.906 & $1321(83.4)$ & $1121(92.6)$ & $<0.001$ & $438(69.4)$ & $399(74.3)$ & 0.064 \\
\hline Single/divorced/widow-ed & $22(1.7)$ & $32(1.8)$ & 0.906 & $263(16.6)$ & $90(7.4)$ & $<0.001$ & 193 (30.6) & $138(25.7)$ & 0.064 \\
\hline \multicolumn{10}{|l|}{ Highest education } \\
\hline No education & $191(15.4)$ & $453(25.8)$ & $<0.001$ & $19(1.3)$ & $52(4.8)$ & $<0.001$ & $44(8.3)$ & $68(15.7)$ & $<0.001$ \\
\hline Primary & $675(54.3)$ & $764(43.5)$ & $<0.001$ & $1004(69.2)$ & $791(72.7)$ & 0.050 & $268(49.8)$ & $221(50.9)$ & 0.676 \\
\hline Secondary or more & $377(30.3)$ & $539(30.7)$ & 0.831 & $429(29.5)$ & $244(22.5)$ & $<0.001$ & $225(41.9)$ & $145(33.4)$ & 0.004 \\
\hline \multicolumn{10}{|l|}{ Parity } \\
\hline Primiparous & $504(40.0)$ & $674(38.0)$ & 0.262 & $422(26.6)$ & $337(27.7)$ & 0.205 & $161(25.4)$ & 179 (33.3) & 0.006 \\
\hline Multiparous & $756(60.0)$ & $1098(62.0)$ & 0.275 & $1160(73.4)$ & $871(72.3)$ & 0.210 & $465(74.6)$ & $336(66.7)$ & $<0.001$ \\
\hline Had prior miscarriage or stillbirth & $264(20.9)$ & $454(25.6)$ & 0.003 & $63(4.0)$ & $65(5.4)$ & 0.165 & $40(6.3)$ & $24(4.5)$ & 0.165 \\
\hline \multicolumn{10}{|l|}{ Wealth quintile } \\
\hline Poorest (<20th percentile) & $201(15.9)$ & $636(35.8)$ & $<0.001$ & $238(15)$ & $282(23.3)$ & $<0.001$ & $167(26.1)$ & 89 (16.6) & $<0.001$ \\
\hline Poor (20th-39th percentile) & $156(12.4)$ & $357(20.1)$ & $<0.001$ & $314(19.7)$ & $284(23.4)$ & 0.021 & $104(16.4)$ & $106(19.7)$ & 0.141 \\
\hline Middle (40th-59th percentile) & $277(22)$ & $353(19.9)$ & 0.164 & $284(17.9)$ & $229(18.8)$ & 0.505 & $120(18.9)$ & $115(21.4)$ & 0.292 \\
\hline Rich (60th-79th percentile) & $331(26.2)$ & $255(14.4)$ & $<0.001$ & $316(19.9)$ & $234(19.2)$ & 0.684 & $160(25.2)$ & $125(23.2)$ & 0.436 \\
\hline Richest (80th-99th percentile) & $296(23.5)$ & $175(9.8)$ & $<0.001$ & $438(27.5)$ & $186(15.3)$ & $<0.001$ & $83(13.1)$ & $102(18.9)$ & 0.006 \\
\hline Has health insurance & $333(26.4)$ & $536(30.2)$ & 0.022 & - & - & - & - & - & - \\
\hline
\end{tabular}

I intervention, $C$ comparison

A composite ANC services index score (maximum score $=12$ ) was computed based on the quality of ANC services women received. The average score in all sites in all countries was above 9, except in the comparison site in Cambodia, where the average ANC index score was 7.8. In each country, women had significantly higher ANC services index scores in the intervention compared to the comparison sites. Table 3 shows the various individual ANC services received by women in each country, with significant differences between intervention and comparison sites for some services.

SBA during delivery was significantly higher in the intervention sites in Cambodia (99.1\% vs $84.8, p<0.001)$. While over $90 \%$ of women reported SBA during delivery in Kenya and Zambia, there were no significant differences between the intervention and comparison sites. In Cambodia, most women reported SBA from a midwife, while in Kenya and Zambia, majority of women received
SBA from a nurse. Among the women who did not have SBA during delivery, the majority had a traditional birth assistant at delivery for Cambodia, whereas in Kenya and Zambia, the majority of those without SBA at delivery obtained care from a relative, friend or neighbor.

\section{Community health worker services}

In all three countries, a significantly greater proportion of women in the intervention sites compared to comparison sites received at least one visit from a $\mathrm{CHW}$ during their last pregnancy (Table 4). The mean number of $\mathrm{CHW}$ visits varied between countries. In Zambia, more than $75 \%$ of women did not receive any visit from a CHW (76\% in intervention sites and $89.9 \%$ in comparison sites, $p<0.001$ ), while in Cambodia, $70 \%$ of the women in intervention sites reported at least 1-2 CHW visits, and $65.5 \%$ reported no $\mathrm{CHW}$ visits in the comparison sites. In all three countries regardless of 


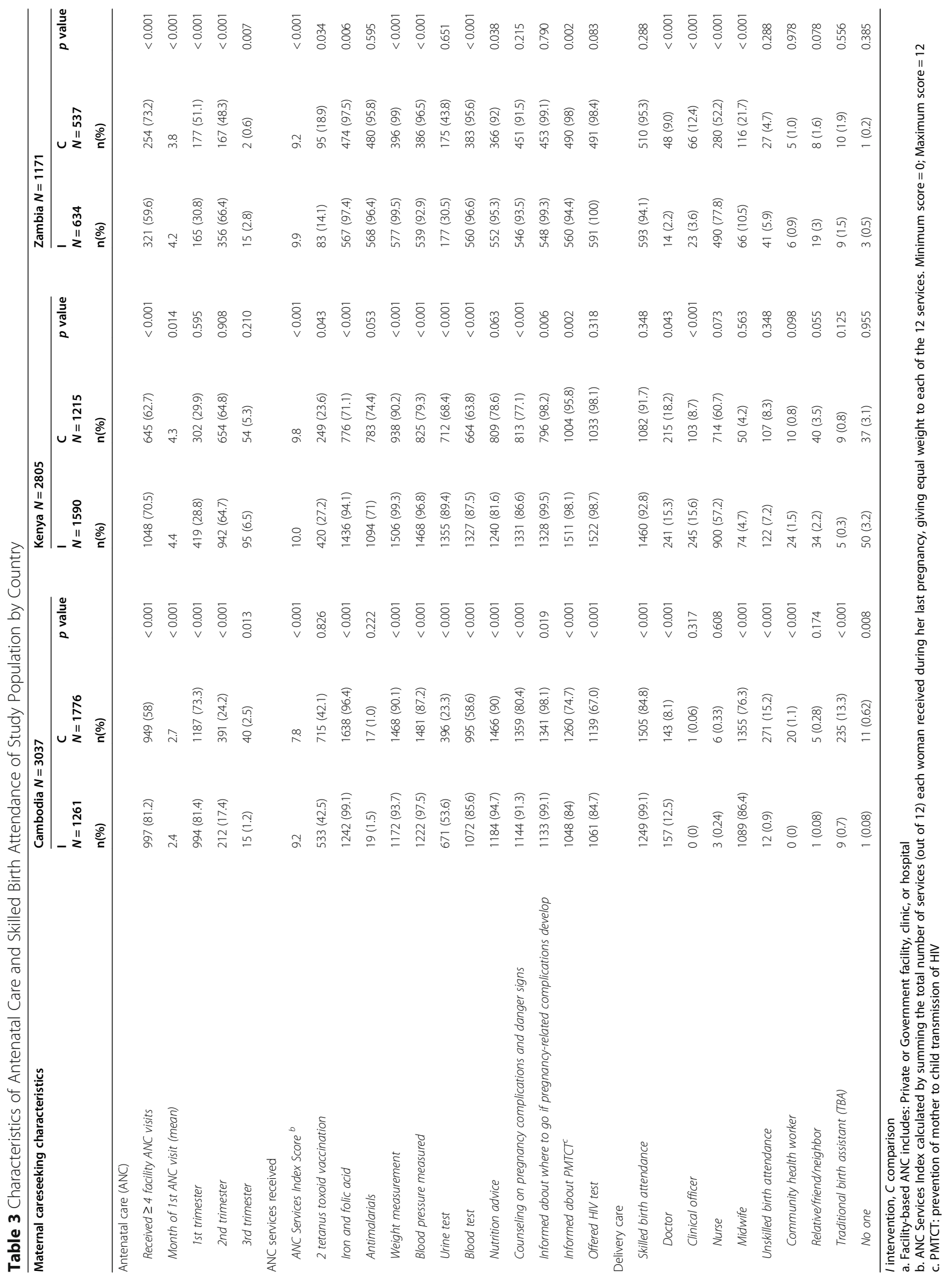


treatment site, less than one-fourth of women received 3-4 CHW visits, and less than $5 \%$ of women received more than $4 \mathrm{CHW}$ visits during their last pregnancy, except for the intervention sites in Kenya (10.5\%). Across all countries, about one third of the CHW visits occurred during the 1st trimester.

Over $95 \%$ of women in all sites reported that the $\mathrm{CHW}$ was courteous and respectful and were satisfied with the CHW services. There were no significant differences between intervention and comparison sites, except in Kenya in terms of CHW service satisfaction, where women from intervention sites reported slightly higher levels of satisfaction $(97.9 \%$ vs $93.6 \%, p=0.002)$. In all three countries, most women reported that CHWs provided counseling during home visits with significant differences between intervention and comparison sites for Cambodia $(94.9 \%$ vs $69.8 \%, p<0.001)$ and Zambia (99.3\% vs. $88.7 \%, p<0.02)$. CHWs in intervention sites were significantly more likely to use counseling aids and storybooks during their visits, discuss pregnancy complications and danger signs with the woman, and include influential family members in the discussions compared to comparison sites in all three countries. For Cambodia and Kenya, over $90 \%$ of women reported that CHWs facilitated their access to ANC, in contrast to Zambia (53.3\% in intervention sites and $84.6 \%$ in comparison sites). Approximately $90 \%$ of the women in the intervention and comparison sites in Kenya reported that CHWs made a follow-up visit after they were referred to or visited a health center, whereas in Cambodia and Zambia, it was lower, 75 and $50 \%$ in the intervention and comparison sites.

\section{Regression analysis}

Table 5 shows results from the univariate and multivariate logistic regression analysis. Controlling for other factors, women 24 years or older had significantly greater odds $(\mathrm{aOR}=1.65$; 95\% CI: $1.14,2.39, p<0.01)$ of receiving SBA in Cambodia. There was no significant association between age and SBA in Kenya and Zambia. Women with primary or secondary education had greater odds of receiving SBA compared to women with no education in Cambodia. Multiparous women compared to primiparous women and those in the wealth quintile equal to or above the 40th percentile compared to women whose wealth was less than the 40th percentile, who were otherwise similar on controlled factors, were significantly more likely to receive SBA. Women in the intervention sites in Cambodia had 7.5 times greater odds (aOR $=7.48 ; 95 \%$ CI: $3.87,14.5)$ of receiving SBA compared to women in the comparison sites. The reverse was true for Kenya, where women had lower odds of having SBA at delivery in the intervention sites compared to the comparison sites $(\mathrm{aOR}=0.60 ; 95 \% \mathrm{CI}$ : 0.41 ,
0.85). There was no significant association between the study sites for SBA in Zambia.

The odds of SBA were significantly higher for women who received four or more facility-based ANC visits for all three countries controlling for other factors. For Cambodia and Kenya, for every additional ANC service received (i.e., a one-point increase in the ANC Index Score), women were 1.13 times (95\% CI: 1.08, 1.19) and 1.19 times $(95 \%$ CI: 1.13, 1.24) more likely to receive SBA.

Though there was a significant positive dose-effect between the number of $\mathrm{CHW}$ visits and delivery with SBA in the univariate analysis for Cambodia and Kenya, this significance was no longer evident in the multivariate analysis. Controlling for other factors, women in Kenya and Zambia had a greater odds of SBA at delivery if the CHW included influential family members in discussions (Kenya aOR $=2.12 ; 95 \%$ CI: 1.06, 4.26; Zambia, aOR = 6.78; 95\% CI: 1.15, 13.9), and in all three countries, if the CHW conducted a follow up visit after a referral to a health care center (Cambodia, aOR $=2.44 ; 95 \% \mathrm{CI}: 1.30$, 4.60; Kenya, $\mathrm{aOR}=2.17$; 95\% CI 1.25, 3.75; Zambia, $\mathrm{aOR}=1.89 ; 95 \% \mathrm{CI}: 1.05,2.02)$. Other components of $\mathrm{CHW}$ pregnancy-related services were not significantly associated with presence of SBA at delivery in the multivariate analyses.

\section{Discussion}

It is postulated that more than $80 \%$ of maternal deaths can be prevented with supervision by a skilled professional at delivery $[9,27]$. The findings from this study provide some evidence of the effectiveness of integrated community interventions focused on timed and targeted $\mathrm{CHW}$ health promotion to promote appropriate careseeking in all study sites. Reported SBA was significantly higher for the intervention sites only for Cambodia, though over $90 \%$ reported SBA during delivery in both intervention and comparison sites for Kenya and Zambia. The type of SBA varied by country, mostly midwives and nurses in Kenya and Zambia. Other women sought care from traditional birth attendants in Cambodia and from friends, neighbors or relatives in Kenya and Zambia. It is apparent that the importance of SBA during delivery needs further emphasis in health promotion messaging during $\mathrm{CHW}$ household visits.

The key predictors of SBA, which varied across countries, were woman's educational status, women aged 24 or more years, multiparity, higher wealth quintiles, four or more ANC visits, and number of ANC services, similar to findings reported in other studies [13-16]. CHWrelated factors that showed a significant effect on likelihood of SBA were the inclusion of other family members in the decision making by CHWs and $\mathrm{CHW}$ follow up visits after referral or visit to the health facility. A study in Kenya on intent of SBA at ANC, also showed similar 


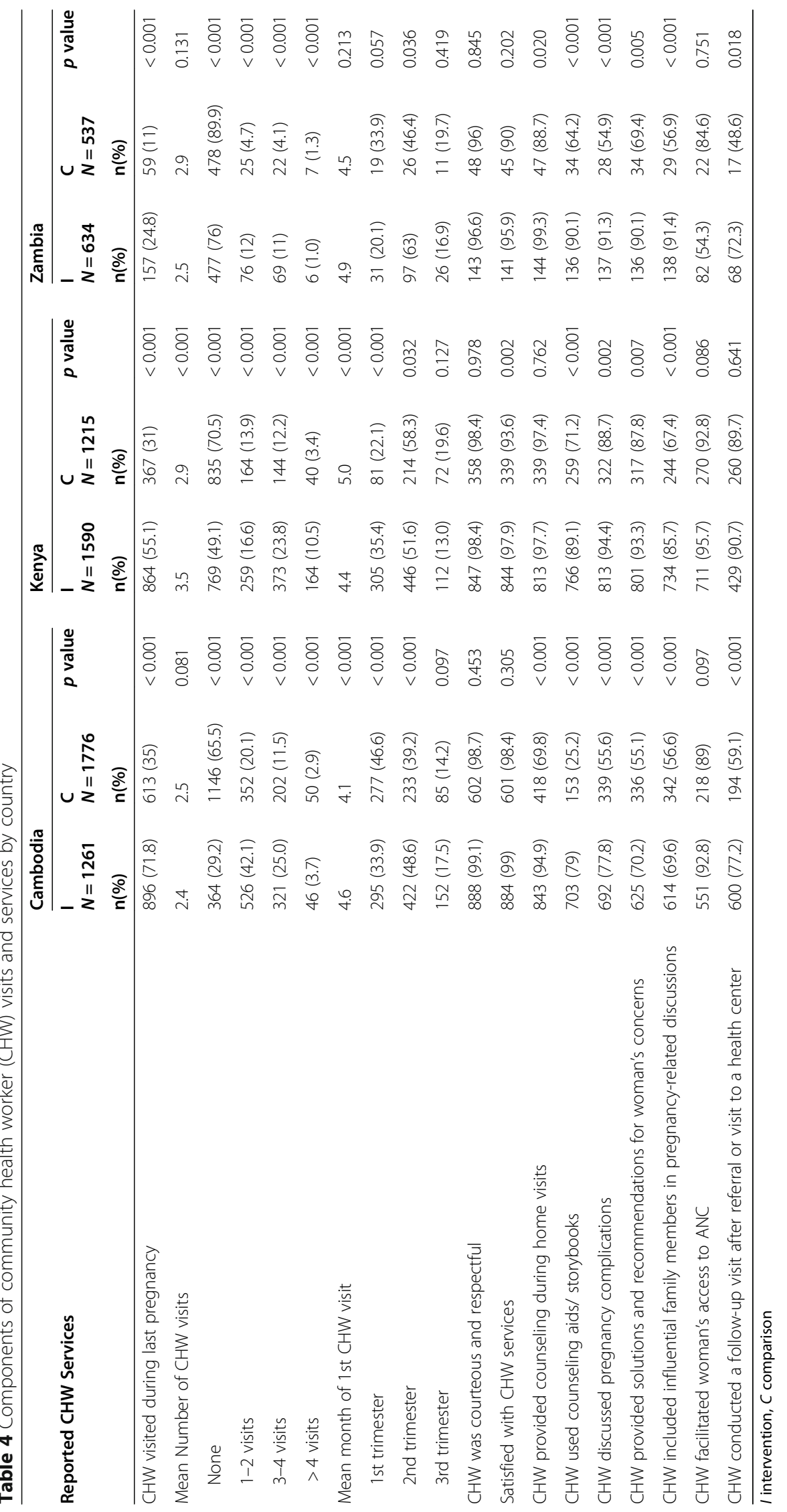




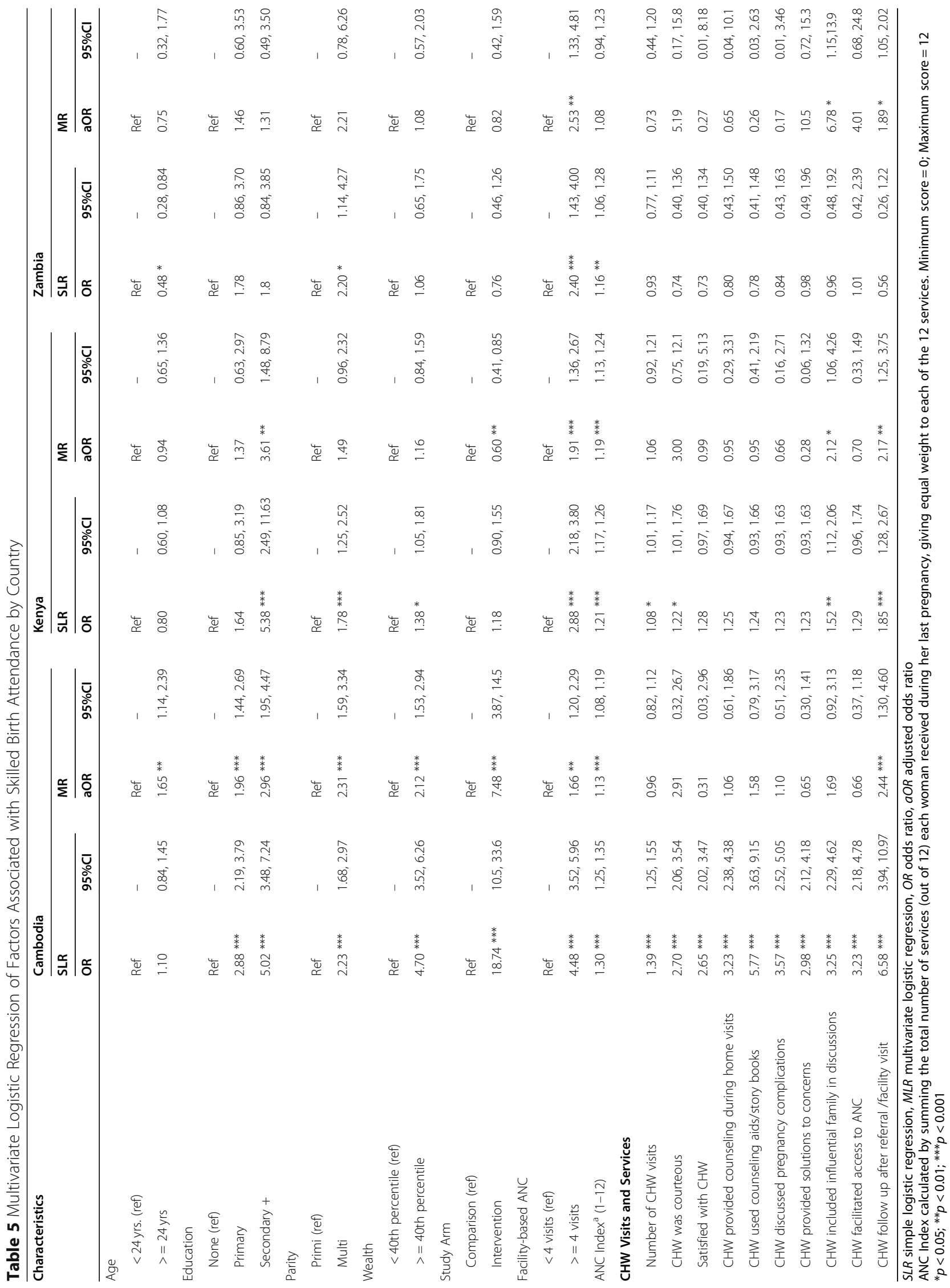


predictors; cost, educational level, number of ANC visits, and provider gender were significantly associated with women's intent to deliver with an SBA [16].

Several studies have shown strong associations between ANC visits and SBA [28-30]. ANC also ensures the maternal care continuum as women who obtain ANC are more likely to access facility services for delivery and postnatal care [31]. Our study showed similar results as the number and type of ANC visits were key predictors of SBA. Women with 4 or more ANC visits had significantly higher odds of delivery with SBA, and ANC service index was significantly associated with the interventions in both Cambodia and Kenya. The specific components of ANC services included in our ANC index were not fully examined in previous studies [28-30].

A selected review of studies showed that differences in the extreme wealth deciles (as opposed to quintiles) were much larger than between the quintiles [32], highlighting the need to target additional support and CHW visits to these economically vulnerable households. Our study showed economic inequities, as women from lower wealth quintiles reported lower presence of SBA during delivery. Another multi-country analysis indicated that absolute household income was a better predictor of SBA wealth indices [33]. Absolute income was not considered in our model and may provide a better understanding of care-seeking patterns for SBA.

Evidence from other studies has shown that $\mathrm{CHW}$ visits during pregnancy have been significantly associated with increased SBA [34-37]. In our study population across three countries, we observed that a significantly higher proportion of women in the intervention sites reported $\mathrm{CHW}$ visits than women in comparison sites. Comparing intervention sites across countries, a greater proportion of women in Cambodia received CHW visits (71.8\%) compared to Kenya (55.1\%) and Zambia, where only one quarter of women (24.8\%) received at least one $\mathrm{CHW}$ visit. These differences are likely due to other contextual factors. In Zambia, the CHWs were volunteers who had been initially recruited and trained by the ministry as Safe Motherhood Action Groups. Evidence from qualitative findings from this study, which are not included here, demonstrated major challenges in the implementation of timed and targeted counseling by CHWs in Zambia, including the lack of transport to reach remote households. High $\mathrm{CHW}$ attrition rates and low levels of satisfaction among CHWs were also reported. In Cambodia, a national policy limiting two CHWs per village was a major barrier to care, as the CHWs felt overwhelmed to meet the demands and expectations for service delivery. Data from the CHW qualitative findings also showed that the support systems for CHW supervision and oversight were also suboptimal, which may have resulted in the lack of a dose-effect between the number of CHW visits and SBA.

Despite the expansion of primary health care systems, $\mathrm{CHW}$ activities and service delivery vary greatly across and even within countries $[18,38]$. Location and frequency of $\mathrm{CHW}$ visits during the antenatal period, and the number and content of counseling messages delivered can vary even within large-scale integrated $\mathrm{CHW}$ programs $[18,39]$. This is likely due to the lack of standardization and sparse data on optimizing $\mathrm{CHW}$ service delivery. One study conducted in Nigeria showed that there was a positive dose-effect on several maternal and child health indicators from the intensity of $\mathrm{CHW}$ services delivered, measured by the number of one-onone advice and assistance sessions provided in addition to standard pregnancy-related education and counseling [40]. Other studies have also looked at the dose-effect of $\mathrm{CHW}$ services on maternal care seeking practices but focused mostly on CHW program intensity. Karim et al. illustrated that a composite measure of time spent with the woman and number of counseling messages delivered was associated with improvements in ANC, iron supplementation, birth preparedness measures, and postnatal care, but not with facility deliveries or SBA [41]. Though we found a dose effect between number of CHW visits and SBA in the univariate analysis for Cambodia and Kenya, these results were no longer significant when controlled for other confounders.

Incentivizing $\mathrm{CHW}$ s with direct compensations as the accredited ASHA program in India, where CHWs perform a wide range of services, may be considered in these rural contexts [42]. The management of these systems need to be carefully regulated, as they have shown that incentives are both empowering and a source of distress due to low incentive rates relative to work expectations, irregular and/or incomplete payment, and the tendency to focus on highly incentivized services rather than client priorities.

For Kenya and Zambia, women were significantly more likely to have SBA at delivery if the CHW had involved influential family members in discussions with the woman. While this finding was not significant in Cambodia in multivariate analysis, there was a positive association in the univariate analysis. Our findings are supported by studies from various countries that have demonstrated that a key component to establishing this trust was ensuring male involvement in the woman's care $[38,43]$. In Uganda, this was most pronounced in terms of birth preparedness, as men still dominate economic power and related decision making in many households [38]. However, when the husband was part of counselling during pregnancy, decision making around saving money to pay for delivery care and seeking care was perceived to be easier for the woman and 
family in general [38]. In Ethiopia, participation in family meetings was significantly associated with an increase in the reported completeness of maternal and newborn health care that women received during birth and the early postnatal period, even after controlling for sociodemographic characteristics and maternal and newborn use of health services [43]. Furthermore, this study also showed that women who had both antenatal care and family participation in their care were most likely to have SBA for delivery [43]. In many LMIC, especially in sub-Saharan Africa and Southeast Asia, women often do not have decision-making power with regard to health service utilization $[16,38,44]$. Thus, the involvement of other key household members, such as husbands and mothers-in-laws, may be beneficial for effective $\mathrm{CHW}$ health promotion.

The sociocultural environment was another critical factor for optimizing CHW functionality. In Cambodia, kinship, social hierarchical structures, religion, patronclient relations and collectivism were shown to impact the ability of CHWs to form relationships and influence decision-making for service utilization [45]. The CHW system in Cambodia fosters a strong identity with a structured induction training and support led by local government bodies that includes basic skills, such as communication and behavior change technique [45]. Furthermore, literature on the impact of $\mathrm{CHW}$ use of support tools demonstrates that having culturally appropriate tools, such as narratives available through videos and storybooks, can be an important and cost effective aid to CHWs, as illustrated in a study from Pakistan, where such tools facilitated dialogue between men and women to create greater awareness of maternal care [46]. This is important to understand because while our study did not show a significant association between the use of counseling aids and storybooks and SBA, this aspect of $\mathrm{CHW}$ services may still be paramount for their ultimate impact on maternal care.

Women were also significantly more likely to have SBA during delivery if a $\mathrm{CHW}$ had conducted one or more follow-up visits after a referral or visit the woman after a health center visit. This finding is supported by a study from Uganda where follow-up and feedback of mothers who had been referred to higher levels of care was perceived to be important in creating accountability for referral compliance and fostering confidence in the CHW service [38]. This enabled them to successfully complete the maternal and newborn care practices recommended by the CHW [38]. Another example is the Family Health Program in Brazil, which demonstrated how effective and formal integration of CHWs into the healthcare system can improve maternal and child care-seeking behaviors [43].
Most CHW studies involve interventions with many components of service delivery, making it difficult to isolate the individual effects of each component [44]. The lack of a statistically significant finding on health outcomes may be attributed to weak implementation fidelity and lack of process optimization of the individual components within the program design [44]. The mechanisms for $\mathrm{CHW}$ recruitment, training, management and support are central to the quality of services that they deliver.

Complimentary social accountability mechanisms using community scorecards combined with $\mathrm{CHW}$ services, have shown to enhance maternal and health outcomes in Malawi and India [8, 31, 47]. These strategies provide a forum to address social determinants of health and positively influence the utilization of healthcare services by creating effective accountability structures, fostering transparent dialogues with community entities and health providers at the primary care facilities, and enhancing performance of providers to deliver equitable quality of care. Though this study did not explore the effects of the integrated approach of $\mathrm{CHW}$ home visits and social accountability mechanisms independently, use of services improved significantly in the intervention sites for number of ANC services received, though SBA at delivery was only significant for Cambodia. Further investigation of the independent and combined effects of social accountability mechanisms and $\mathrm{CHW}$ services is warranted and can enhance and optimize CHW service delivery.

We report several potential study limitations. The quasi experimental cross-sectional design does not allow for causal inferences about the effectiveness of the integrated interventions on maternal care seeking practices. Recall bias on timing and number of CHW visits by the women may be another factor for bias in this study, as the woman's recall was not corroborated with the CHW visit records. Thirdly, the dose effect of CHW visits can only be ascertained with additional data on the time spent during home visits, content covered and the quality of the visits; these data were not captured in our study. Certification or training of midwives was not evaluated in this study; thus, the inclusion of midwives in the definition of SBA may be considered another potential limitation. Finally, we acknowledge that the broad spectrum of health and development interventions, including the establishment or strengthening of community councils and ongoing $\mathrm{CHW}$ services in the comparison sites, also contributed to increased SBA utilization for delivery care. These effects were not independently examined with a difference in difference analysis.

\section{Conclusion}

This study provides some evidence that communityoriented interventions which address the number and nature of $\mathrm{CHW}$ service delivery components for 
maternal and child health promotion can increase the likelihood of SBA during delivery. A standard minimum number of $\mathrm{CHW}$ visits, while also considering the unique sociocultural contexts of different LMICs, should be evidenced-based. CHW communication skills to build rapport and trust with mothers and families should be paramount in promoting appropriate care seeking. Complementary community-level interventions to enhance social accountability to ensure equitable access to and utilization of quality services at the primary care level need to be empirically explored in the future. Despite the limitations, the study findings provide some evidence that effective engagement of CHWs and social accountability mechanisms with community entities can enhance access to safe deliveries for women in these rural communities.

\section{Supplementary information}

Supplementary information accompanies this paper at https://doi.org/10. 1186/s12884-020-03223-0.

\section{Additional file 1.}

\section{Abbreviations}

CHW: Community Health Worker; SBA: Skilled Birth Attendance;

ANC: Antenatal Care

\section{Acknowledgements \\ The authors would like to acknowledge the contributions of the research and survey teams in Cambodia, Zambia and Kenya, and the support received from the Ministry of Health and World Vision staff in each country. We would also like to thank the study participants for their time. We are also grateful for the valuable insight and feedback from the reviewers and the editorial team.}

\section{Authors' contributions}

$A E, G E$ and $H P$ designed and conducted the research study. AE and AK wrote the original manuscript and conceptualized the analysis. AK and $Y J$ performed the analysis. HP, JC, AHG and YJ, reviewed and contributed to the final draft. All authors read and approved the final manuscript.

\section{Funding}

The study was conducted through a research grant \# 113543 to Johns Hopkins University from World Vision. The funding organization was not involved in the data collection, analysis or interpretation of the findings.

\section{Availability of data and materials}

Data sets used for analysis for the current research are not publicly available as the research was performed under a contractual agreement, but available from the corresponding author upon reasonable request.

\section{Ethics approval and consent to participate}

The study was part of a larger research trail that was conducted in Cambodia, Guatemala, Kenya and Zambia. Ethical clearance was obtained from the Johns Hopkins Bloomberg School of Public Health Institutional Review Board (IRB \# 00004986), and the Institutional Review Boards of the local research institutions (National Institute of Public Health in Cambodia, Moi University School of Public Health in Kenya, and the Institute for Economic and Social Research at the University of Zambia. Based on the country ethical protocols, written informed consent in the local language was obtained from all study participants in Kenya (Swahili) and Zambia (Tonga, Nyanja, Lozi), and verbal informed consent was obtained from all study participants in Cambodia (Khmer), prior to administering the surveys and privacy and confidentiality was ensured. The consent procedures were approved by the institutional review boards in all countries and the Johns Hopkins Bloomberg School of Public Health.

\section{Consent for publication}

Not applicable.

\section{Competing interests}

The study was conducted through a research grant (\#113543) to Johns Hopkins University. AE, YJ, HP and GE were partially funded by the grant to conduct the research. JC and AHG were employed by World Vision. We declare no other competing interests.

\section{Author details}

'Department of International Health, Johns Hopkins Bloomberg School of Public Health, 615 N Wolfe St, Baltimore, MD 21205, USA. ${ }^{2}$ Johns Hopkins Medical Institutions, 733 North Broadway, Baltimore, MD 21205-2196, USA. ${ }^{3}$ Moi University School of Public Health, Eldoret, Kenya. ${ }^{4}$ WHO Timor-Leste Office United Nations House Caicoli street, Dili, Timor-Leste. ${ }^{5}$ Department of Global Health, University of Washington, Seattle, WA, USA. ${ }^{6}$ World Vision International, Washington DC, USA.

Received: 30 October 2019 Accepted: 31 August 2020

Published online: 05 September 2020

\section{References}

1. Skilled attendants at birth. https://www.who.int/gho/maternal_health/ skilled_care/skilled_birth_attendance_text/en/. Accessed 28 Nov 2018.

2. World Health Organization, Unicef: Trends in maternal mortality: 1990-2015: estimates from WHO, UNICEF, UNFPA, World Bank Group and the United Nations Population Division. 2015.

3. Team UST. Review of the contributions of the MDG agenda to foster development: lessons for the post-2015 UN development agenda. In: UN System Task Team; 2012.

4. Crowe S, Utley M, Costello A, Pagel C. How many births in sub-Saharan Africa and South Asia will not be attended by a skilled birth attendant between 2011 and 2015? BMC Pregnancy and Childbirth. 2012;12(1):4.

5. World Health Organization. Strategies toward ending preventable maternal mortality (EPMM). Geneva: World Health Organization; 2015. p. 2015.

6. McDonagh $\mathrm{M}$. Is antenatal care effective in reducing maternal morbidity and mortality? Health Policy Plan. 1996;11(1):1-15.

7. Graham WJ, Bell JS, Bullough CH: Can skilled attendance at delivery reduce maternal mortality in developing countries? Safe motherhood strategies: a review of the evidence 2001

8. Safer MP. Making pregnancy safer: the critical role of the skilled attendant. Geneva: World Health Organization; 2004.

9. Ronsmans C, Graham WJ, group LMSSs. maternal mortality: who, when, where, and why. Lancet. 2006:368(9542):1189-200.

10. Ross JA, Blanc AK. Why aren't there more maternal deaths? A decomposition analysis. Matern Child Health J. 2012;16(2):456-63.

11. Tura G, Fantahun M, Worku A. The effect of health facility delivery on neonatal mortality: systematic review and meta-analysis. BMC Pregnancy Childbirth. 2013;13(1):18.

12. Biemba G, Yeboah-Antwi K, Semrau K, Hammond E, Hamer D: Who is assisting women to deliver babies within health facilities. An Analysis of Deliveries in Four Provinces in Zambia Austin J Public Health Epidemiol 2014, 1(2):1007.

13. Mengesha ZB, Biks GA, Ayele TA, Tessema GA, Koye DN. Determinants of skilled attendance for delivery in Northwest Ethiopia: a community based nested case control study. BMC Public Health. 2013;13(1):130.

14. Dickson KS, Amu H. determinants of skilled birth attendance in the northern parts of Ghana. Adv Public Health. 2017;2017.

15. Gitimu A, Herr C, Oruko H, Karijo E, Gichuki R, Ofware P, Lakati A, Nyagero J. Determinants of use of skilled birth attendant at delivery in Makueni, Kenya: a cross sectional study. BMC Pregnancy Childbirth. 2015;15(1):9,

16. Nyongesa C, Xu X, Hall JJ, Macharia WM, Yego F, Hall B. Factors influencing choice of skilled birth attendance at ANC: evidence from the Kenya demographic health survey. BMC Pregnancy Childbirth. 2018;18(1):88

17. Perry HB, Rassekh BM, Gupta S, Wilhelm J, Freeman PA. Comprehensive review of the evidence regarding the effectiveness of community-based primary health care in improving maternal, neonatal and child health: 1. rationale, 
methods and database description. J Glob Health. 2017;7(1):010901. https://doi. org/10.7189/jogh.07.010901. PMID: 28685039; PMCID: PMC5491943.

18. Perry H, Zulliger R. How effective are community health workers. An overview of current evidence with recommendations for strengthening community health worker programs to accelerate progress in achieving the health-related Millennium Development Goals. Baltimore: Johns Hopkins Bloomberg School of Public Health; 2012.

19. Ho LS, Labrecque G, Batonon I, Salsi V, Ratnayake R. Effects of a community scorecard on improving the local health system in eastern Democratic Republic of Congo: qualitative evidence using the most significant change technique. Confl Heal. 2015;9(1):27.

20. Edward A, Osei-Bonsu K, Branchini C, Shah Yarghal T, Arwal SH, Naeem AJ. enhancing governance and health system accountability for people centered healthcare: an exploratory study of community scorecards in Afghanistan. BMC Health Serv Res. 2015;15(1):299.

21. Hamal M, de Cock BT, De Brouwere V, Bardají A, Dieleman M. How does social accountability contribute to better maternal health outcomes? A qualitative study on perceived changes with government and civil society actors in Gujarat, India. BMC Health Serv Res. 2018;18(1):653.

22. Mafuta EM, Dieleman MA, Essink L, Khomba PN, Zioko FM, Mambu TN, Kayembe PK, de Cock BT. Participatory approach to design social accountability interventions to improve maternal health services: a case study from the Democratic Republic of the Congo. Glob Health Res Policy. 2017;2(1):4.

23. Schaaf M, Topp SM, Ngulube M. From favours to entitlements: community voice and action and health service quality in Zambia. Health Policy Plan. 2017:32(6):847-59.

24. The Global Fund. Community systems strengthening framework. Geneva: The Global Fund; 2010

25. WHO Recommendations on Antenatal Care for a Positive Pregnancy Experience. Geneva: World Health Organization; 2016. PMID: 28079998

26. StataCorp Stata 14. In., 14.2 edn. Texas, 2015

27. World Health Organization, UNICEF: Reduction of maternal mortality: a joint WHO/UNFPA/UNICEF/World Bank Statement. 1999.

28. Abou-Zahr CL, Wardlaw TM, Organization WH: Antenatal care in developing countries: promises, achievements and missed opportunities: an analysis of trends, levels and differentials, 1990-2001. 2003.

29. Amoakoh-Coleman M, Ansah EK, Agyepong IA, Grobbee DE, Kayode GA Klipstein-Grobusch K. Predictors of skilled attendance at delivery among antenatal clinic attendants in Ghana: a cross-sectional study of population data. BMJ Open. 2015;5(5):e007810.

30. Nair M, Ariana P, Webster P. What influences the decision to undergo institutional delivery by skilled birth attendants? A cohort study in rural Andhra Pradesh, India. Rural \& Remote Health. 2012;12(4).

31. Edward A, Jung Y, Ettyang G, Chege J, Ghee AE. Applying an Equity Lens to Maternal Health Care Continuum in Rural Communities of Cambodia, Guatemala, Kenya, and Zambia. Int Med Rev. 2018;4(2).

32. Wong KL, Restrepo-Méndez MC, Barros AJ, Victora CG. Socioeconomic inequalities in skilled birth attendance and child stunting in selected low and middle income countries: wealth quintiles or deciles? PLoS One. 2017; 12(5):e0174823.

33. Joseph G, da Silva IC, Fink G, Barros AJ, Victora CG. Absolute income is a better predictor of coverage by skilled birth attendance than relative wealth quintiles in a multicountry analysis: comparison of 100 low-and middleincome countries. BMC Pregnancy Childbirth. 2018;18(1):104.

34. Viswanathan K, Hansen PM, Rahman MH, Steinhardt L, Edward A, Arwal SH, Peters DH, Burnham G. Can community health workers increase coverage of reproductive health services? J Epidemiol Community Health. 2012;66(10): 894-900.

35. Mayhew M, Hansen PM, Peters DH, Edward A, Singh LP, Dwivedi V, Mashkoor A, Burnham G. Determinants of skilled birth attendant utilization in Afghanistan: a cross-sectional study. Am J Public Health. 2008;98(10): 1849-56.

36. Agarwal S, Curtis S, Angeles G, Speizer I, Singh K, Thomas J. Are community health workers effective in retaining women in the maternity care continuum? Evidence from India. BMJ Glob Health. 2019;4(4):e001557.

37. Sacks E, Freeman PA, Sakyi K, Jennings MC, Rassekh BM, Gupta S, Perry HB. Comprehensive review of the evidence regarding the effectiveness of community-based primary health care in improving maternal, neonatal and child health: 3. neonatal health findings. J Glob Health. 2017;7(1):010903.
38. Okuga M, Kemigisa M, Namutamba S, Namazzi G, Waiswa P. Engaging community health workers in maternal and newborn care in eastern Uganda. Glob Health Action. 2015;8(1):23968.

39. Freeman PA, Gupta S, Rassekh BM, Perry HB. Comprehensive review of the evidence regarding the effectiveness of community-based primary health care in improving maternal, neonatal and child health: 2 . maternal health findings. J Glob Health. 2017;7(1):010902. https://doi.org/10.7189/jogh.07. 010902. PMID: 28685040; PMCID: PMC5491947.

40. Findley SE, Uwemedimo OT, Doctor HV, Green C, Adamu F, Afenyadu GY. Comparison of high-versus low-intensity community health worker intervention to promote newborn and child health in northern Nigeria. Int J Women's Health. 2013;5:717.

41. Karim AM, Admassu K, Schellenberg J, Alemu H, Getachew N, Ameha A, Tadesse L, Betemariam W. Effect of Ethiopia's health extension program on maternal and newborn health care practices in 101 rural districts: a doseresponse study. PLoS One. 2013;8(6):e65160.

42. Sarin E, Lunsford SS, Sooden A, Rai S, Livesley N. The mixed nature of incentives for community health workers: lessons from a qualitative study in two districts in India. Front Public Health. 2016;4:38.

43. Barry DFA, Mohammed H, Desta BF, Tadesse L, Aklilu Y. The effect of community maternal and newborn health family meetings on type of birth attendant and completeness of maternal and newborn care received during birth and the early postnatal period in rural Ethiopia. J Midwifery Women's Health. 2014;59:544-54.

44. King RJR, Dietsch E. Barriers and facilitators to accessing skilled birth attendants in Afar region, Ethiopia. Midwifery. 2015;31:540-6.

45. Ozano K, Simkhada P, Thann K, Khatri R. Improving local health through community health workers in Cambodia: challenges and solutions. Hum Resour Health. 2018;16(1):2.

46. Hargraves JL, Bonollo D, Person SD, Ferguson WJ. A randomized controlled trial of community health workers using patient stories to support hypertension management: study protocol. Contemporary Clin Trials. 2018; 69:76-82.

47. Lodenstein E, Ingemann C, Molenaar JM, Dieleman M, Broerse JE. Informal social accountability in maternal health service delivery: a study in northern Malawi. PLoS One. 2018;13(4):e0195671.

\section{Publisher's Note}

Springer Nature remains neutral with regard to jurisdictional claims in published maps and institutional affiliations.

\section{Ready to submit your research? Choose BMC and benefit from:}

- fast, convenient online submission

- thorough peer review by experienced researchers in your field

- rapid publication on acceptance

- support for research data, including large and complex data types

- gold Open Access which fosters wider collaboration and increased citations

- maximum visibility for your research: over $100 \mathrm{M}$ website views per year

At BMC, research is always in progress.

Learn more biomedcentral.com/submissions 